\title{
Outcomes of allogeneic stem cell transplantation among patients with acute myeloid leukemia presenting active disease: Experience of a single European Comprehensive Cancer Center
} \author{
Susana Roncon ${ }^{4}$, António Campos-JÚnior ${ }^{5}$

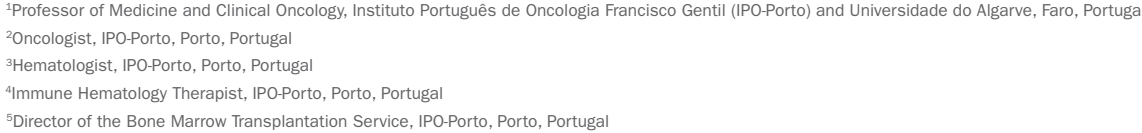

Ramon Andrade Bezerra de-Mello ${ }^{1 *}$, Carlos Pinho-Vaz ${ }^{2}$, Rosa Branca ${ }^{3}$, Fernando Campilho ${ }^{3}$, Maria Rosales ${ }^{4}$,

Study conducted at Instituto Português de Oncologia Francisco Gentil (IPO-Porto), Porto, Portugal and at Departamento de Ciências Biomédicas e Medicina, Universidade do Algarve, Faro, Portugal

Article received: $7 / 7 / 2015$ Accepted for publication: 7/19/2015

*Correspondence: Departamento de Transplantação de Medula Óssea Address: Rua Dr. António Bernardino de Almeida

Porto, Portugal Postal code: 4200-072 ramondemello@gmail.com

http://dx.doi.org/10.1590/1806-9282.62.07.641

Conflicts of interest: The authors declare no conflicts of interest in this study. Ramon Andrade de-Mello is a consultant for Pfizer Advisory Board, National Science Centre, Poland, and has received an Educational Grant from Pierre Fabre

\section{SUMMARY}

Introduction: Allogeneic hematopoietic stem cell transplantation (ASCT) represents a potentially curative approach for patients with relapsed or refractory acute myeloid leukemia (AML). We report the outcome of relapsed/refractory AML patients treated with ASCT.

Method: A retrospective cohort from 1994 to 2013 that included 61 patients with diagnosis of relapsed/refractory AML. Outcomes of interest were transplant-related mortality (TRM), incidence of acute and chronic graft-versus-host disease (GVHD), relapse incidence, progression-free survival (PFS) and overall survival (OS). Statistical significance was set at $\mathrm{p}<0.05$.

Results: The median age was 61 years (range 1 to 65). The cumulative incidence of 90 days, 1 year, and 3 years TRM were $60 \%, 26.7 \%$, and $13.3 \%$, respectively ( $\mathrm{p}<0.001$ ). The incidence of relapse was $21.7 \%$ at 1 year, $13 \%$ at 3 years, and $8.7 \%$ at 5 years. Median OS was estimated to be 8 months (95CI 3.266-12.734) and median PFS, 3 months (95CI 1.835-4.165).

Conclusion: In our cohort, TRM in first years after ASCT remains considerable, but ASCT in this setting seems to be a good choice for AML patients with active disease. However, novel approaches are needed to reduce TRM and relapse in this set of patients.

Keywords: acute myeloid leukemia, heterologous transplantation, bone marrow neoplasms.

\section{INTRODUCTION}

Acute myeloid leukemia (AML) is a heterogeneous clonal disorder of hematopoietic progenitor cells which lose their ability to differentiate normally and to respond to normal regulators of proliferation. ${ }^{1,2}$ Intensified treatment and improvement in supportive care have resulted in an enhanced outcome for patients with AML. At diagnosis, AML patients are evaluated by clinical risk factors and are considered for allogeneic stem cell transplantation (ASCT) based on the risk factors. ${ }^{3}$ Cytogenetic abnormalities are among the most widely recognized risk factors in AML patients. ${ }^{4} \mathrm{AML}$ with karyotype $\mathrm{t}(8 ; 21)$, inv(16), $t(16 ; 16)$, and $t(15 ; 17)$ are expected to be controlled with chemotherapy alone, and patients with these forms of AML are thus categorized into a favorable cytogenetic risk group. ${ }^{4,5}$ Therefore, indication of ASCT for patients in this group is considered not at the first complete remission but at the state of relapse, after the second remission or just in case of failure to achieve remission. ${ }^{3,5,6}$ Recent results from clinical trials indicate a 1-year overall survival (OS) rate of 60 to $70 \%{ }^{7-9}$ In children with AML who relapsed post-ASCT and after a second ASCT, it was reported at approximately 30 to $40 \%$ by Lee et al. ${ }^{9}$ In 2013 , survival outcomes were reported to be similar between 
adolescents and children with AML following ASCT. ${ }^{10}$ Myeloablative preparative regimen used for ASCT induces profound neutropenia and platelet decrease. ${ }^{11}$ Prolonged time of recovery from neutropenia is associated with high risk of infections and severe sepsis. Although granulocyte colony-stimulate factors can be used to help in neutrophil recovery, it delays platelet engraftment as well as immune recovery and may increase the incidence of graft-versus-host disease (GVHD), transplant-related mortality (TRM) and death. ${ }^{2,12}$ Nevertheless, ASCT represents a potentially curative approach for patients with relapsed or refractory AML in spite of significant TRM and comorbidity, such as veno-occlusive disease and sepsis. ${ }^{11}$ Several regimens with different dose intensities have been studied as conditioning therapies before ASCT in patients with AML. ${ }^{13}$ In addition, the choice between myeloablative conditioning, non-myeloablative regimens and reduced intensity conditioning regimens depends on the disease behavior as well as patient overall condition and tolerated toxicities, even though outcomes can be questioned. ${ }^{14}$ Thus, ASCT for patients with relapsed/refractory disease could represent an important therapeutic option in order to improve survival in an attempt to control a novel relapse.

Herein, we report the results of a retrospective cohort with the primary endpoint of assessing outcomes in a southern European comprehensive cancer center. We analyzed OS, progression-free survival (PFS), and incidence of relapse after the second ASCT post-high dose induction chemotherapy in patients with relapse/refractory disease. The secondary endpoints of this study were the assessment of TRM and GVHD rate.

\section{Method}

\section{Design}

Our retrospective cohort includes data from January 1994 to January 2013 collected at the Central Comprehensive Cancer Hospital in northern Portugal: the Portuguese Oncology Institute (IPO-Porto), Porto, Portugal. The study was conducted according to the Declaration of Helsinki. Signed written-informed consent form was obtained from all patients involved in this study.

\section{Patients}

The patient inclusion criteria were the following: confirmed diagnosis of relapsed/refractory AML (based on morphological findings of the bone marrow aspirates and immune-phenotype analysis of leukemic cells by flow cytometry or immune histochemical analysis) and adequate hematologic, renal, and hepatic function. Patients who did not meet the inclusion criteria were excluded from this study. Data were collected from clinical records at the participant institution. All patients involved in this study were Portuguese Caucasians.

\section{Treatment regimen}

ASCT was performed on 61 patients in active disease (relapsed/refractory). The preparative regimens and stem cell sources differed between the participants.

\section{Endpoints}

The primary endpoint of our study was OS, which was defined as the period between the date of first recurrence diagnosis and death due to the disease/last medical visit. Progression-free survival was defined as the period between the date of first recurrence diagnosis and the date of second recurrence diagnosis. Complete response (CR) was considered normocellular bone marrow ( $\leq 5 \%$ blast), peripheral blood with neutrophils $\geq 1500 / \mu \mathrm{L}$, absence of any AML sign. Partial response (PR) referred to normocellular bone marrow ( 6 to $25 \%$ blasts) or organic sign of AML. Failure/no response (NR) included patients with clinical disease or bone marrow with $\geq 5 \%$ blasts post-transplant. The secondary endpoints were TRM and incidence of acute and chronic GVHD.

\section{Statistical analysis}

Chi-squared and Wilcoxon-Mann-Whitney tests were used to compare the frequency distributions of variables such as age, sex, TRM, acute and chronic GVHD rates. We analyzed OS and PFS using a Kaplan-Meier curve. All statistical tests were two-sided, and $\mathrm{p}<0.05$ was considered the threshold of statistical significance. All data analyses were performed using IBM ${ }^{\circledR}$ SPSS Statistics, version 22.0 (Chicago, USA).

\section{Results}

\section{Patients' characteristics}

Table 1 and Table 2 summarize the characteristics of the 61 patients involved in our study. Median age was 61 years (1 to 65) and the majority of patients were older than 18 years. Female gender corresponded to $55.7 \%$ of all patients. With respect to French-American-British (FAB) classification, the majority of patients corresponded to M1 (10.3\%), M2 (34.5\%), M4 (10.3\%), and M7 (10.3\%). The mainstay of our cohort was to evaluate outcome of AML patients with active disease. Patients with first relapse were 23 out of 59 (39\%); second resistance relapse, 7 out of 59 (11.9\%); disease not treated, 2 out of 59 (3.4\%); primary resistance relapse, 11 out of 59 (18.6\%); graft 
failure, 11 out of 59 (18.6\%); third relapse, 2 out of 59 (3.4\%). Approximately half of patients were treated with non-myeloablative regimens (55.7\%) and the majority had HLA-related disease (83.9\%). Also, 54 out of $61 \mathrm{pa-}$ tients $(88.5 \%)$ were treated with stem cells from peripheral blood source.

\begin{tabular}{|c|c|c|}
\hline Characteristics & Patients, $\mathbf{n}$ & Rate \% \\
\hline Patients analyzed & 61 & 100 \\
\hline Age, years & $61(1-65)$ & \\
\hline$<2$ years & $1 / 61$ & 1.6 \\
\hline $2-9$ years & $8 / 61$ & 13.1 \\
\hline $10-17$ years & $5 / 61$ & 8.2 \\
\hline $18-45$ years & $24 / 61$ & 39.3 \\
\hline$>45$ years & $23 / 61$ & 37.7 \\
\hline \multicolumn{3}{|l|}{ Sex } \\
\hline Male & $27 / 61$ & 44.3 \\
\hline Female & $34 / 61$ & 55.7 \\
\hline \multicolumn{3}{|l|}{ FAB type } \\
\hline M0 & $2 / 58$ & 3.4 \\
\hline M1 & $6 / 58$ & 10.3 \\
\hline M2 & $20 / 58$ & 34.5 \\
\hline M3 & $1 / 58$ & 1.7 \\
\hline M4 & $6 / 58$ & 10.3 \\
\hline M5 & $5 / 58$ & 8.6 \\
\hline M6 & $1 / 58$ & 1.7 \\
\hline M7 & $6 / 58$ & 10.3 \\
\hline Not classified & $11 / 58$ & 18.9 \\
\hline Missing data & 3 & \\
\hline
\end{tabular}

FAB: French-American-British classification.

TABLE 2 Characteristics of disease status, preparative regimens, and transplant-related issues.

Characteristic

Patients, $\mathbf{n} \%$

\section{Disease status}

\begin{tabular}{lll}
\hline First no treated relapse & $23 / 59$ & 39 \\
\hline Second resistance relapse & $7 / 59$ & 11.9 \\
\hline Disease not treated & $2 / 59$ & 3.4 \\
\hline Primary resistant disease & $11 / 59$ & 18.6 \\
\hline Progressive disease & $1 / 59$ & 1.7 \\
\hline Graft failure & $11 / 59$ & 18.6 \\
\hline Third relapse & $2 / 59$ & 3.4 \\
\hline First relapse - responsive disease & $1 / 59$ & 1.7 \\
\hline Second relapse - responsive disease & $1 / 59$ & 1.7 \\
\hline Missing data & 2 & 3.3 \\
\hline & & (Continue)
\end{tabular}

TABLE 2 (Cont.) Characteristics of disease status,
preparative regimens, and transplant-related issues.

Characteristic

Patients, $\mathbf{n} \%$

\section{Conditioning regimen}

\begin{tabular}{lll}
\hline Myeloablative & 27 & 44.3 \\
\hline Non-myeloablative & 34 & 55.7 \\
\hline
\end{tabular}

\section{Donor status}

\begin{tabular}{lll}
\hline Parents & 3 & 4.9 \\
\hline Siblings & 48 & 78.7 \\
\hline Matched unrelated & 10 & 16.4 \\
\hline
\end{tabular}

\section{HLA}

\begin{tabular}{lll}
\hline Related & $47 / 56$ & 83.9 \\
\hline Mismatched & $9 / 56$ & 16.1 \\
\hline Missing data & 5 & \\
\hline
\end{tabular}

\section{Stem cell source}

\begin{tabular}{lll}
\hline Umbilical cord & $1 / 61$ & 1.6 \\
\hline Bone marrow & $6 / 61$ & 9.8 \\
\hline Peripheral blood & $54 / 61$ & 88.5 \\
\hline Best response & & \\
\hline Complete response & $2 / 23$ & 8.7 \\
\hline Partial response & $3 / 23$ & 13 \\
\hline Failure or no response & $18 / 23$ & 78.3 \\
\hline Not possible to assess* & 38 & \\
\hline
\end{tabular}

\section{Censor}

Overall mortality

Disease-related mortality

$42 / 61$

68.85

Transplant-related mortality

$27 / 61$

44.26

HLA: anti-human leukocyte antigen; * these data were not possible to assess due to transplant-related mortality or early disease-related mortality prior to response assessment.

Outcomes: Clinical response, overall survival, and progression-free survival

In terms of clinical response, 2 out of 23 patients (8.7\%) presented completed response and 3 out of 23 patients (9.8\%) presented partial response. The incidence of relapse was 13 out of 23 patients (56.5\%) in the first 90 days post-ASCT; 5 out of $23(21.7 \%)$ in the first year; 3 out of 23 $(13 \%)$ in the third year; and 2 out of $23(8.7 \%)$ in the fifth year post-ASCT (Table 3). The overall mortality post-ASCT in our set of patients with active disease (relapse or refractory AML) was 42 out of 61 (68.85\%): 15 out of 44 patients due to TRM and 27 out of 44 patients due to AML (Table 2). In addition, mortality was higher in the first 90 days post-ASCT, 20 out of 42 (47.6\%), than in the first year, 18 out of 44 (42.8\%); in the third year, 2 out of 44 (4.7\%); and in the fifth year, 4 out of 44 (9.5\%) post-ASCT, $\mathrm{p}<0.001$. Moreover, median PFS was 3 months (95CI 1.835-4.165) and median OS was 8 months (95CI 3.266-12.734). 
Transplant-related mortality, disease mortality, and graft-versus-host disease

Table 3 summarizes data regarding TRM: 9 out of 15 patients $(60 \%)$ in the 90 days post-ASCT, 4 out of $15(26.7 \%)$ in the first year, 2 out of 15 patients $(13.3 \%)$ in the third year post-ASCT $(\mathrm{p}=0.136)$. Table 3 also shows mortality due to AML: 11 out of 27 patients (40.7\%) in the first 90 days post-ASCT; 14 out of 27 (51.83\%) in the first year; and 4 out of 27 patients $(14.8 \%)$ in the fifth year postASCT ( $p=0.005)$. In spite of the high amount of missing data regarding GVHD status throughout our clinical records, we could verify that 20 out of 47 patients (42.6\%) presented with acute grade II-IV GVHD and 11 out of 17 patients $(64.7 \%)$ presented with chronic grade II-IV GVHD.

\section{Discussion}

AML with active disease (relapsed/refractory) remains a challenge for clinicians worldwide, especially in patients previously treated with ASCT. ${ }^{15}$ In this setting of patients, prognosis is still poor and this group may benefit from new drug developments and alternative approaches for disease control and delay of a novel relapse. ${ }^{16,17}$ In patients with relapsed AML, depending on cytogenetic profile, age and time of first remission, cytarabine-based salvage chemotherapy is sometimes satisfactory. ${ }^{15,18,19}$ However, only a few randomized studies address this issue, which thus remains a gray area. ${ }^{20,21}$ In second line setting, favorable, intermediate or high intermediate group are suitable to SWOG 9126 protocol (high dose cytarabine, daunorubicin and cyclosporine). ${ }^{22,23}$ Our cohort did not provide the cytogenetic profile of the studied population due to the presence of active disease and therefore its irrelevance in this framework. In addition, we included patients since 1994, and, by then, data such as these were not available. ASCT should only be proposed to patients with second remission in case of HLA-matched donor or HLA-mismatched donor depending on age. ${ }^{24}$ Patients in the high-risk group and with time of remission less than 6 months should be referred to clinical trials or better supportive care. ${ }^{25-27}$ In our cohort, 59 out of 61 patients presented active disease, i.e., patients who had failure in previous treatments, including previous ASCT. Despite that, our population was relatively heterogeneous; the present manuscript reports the experience of a large reference Comprehensive Cancer Center in southern Europe that serves a 3 million habitant area in the North of Portugal. Most of our patients were female and with M1, M2, M4, and M7 FAB classification (Table 1). In addition, the donor sample was mostly family-related and HLA-related, which favored our results (Table 2). In terms of response, we observed 2 out of 23 (8.7\%) complete response patients in our cohort and an overall mortality of $68.85 \%$ (42 out of 61 patients). This data reflects the disease aggressiveness of our set of patients. However, it also represents relatively good results compared to best supportive care and others approaches previously published in the literature. ${ }^{26,28}$ Interestingly, in 2013, Ivanoff et al. reported a cohort of 47 patients with acute/ refractory AML, after at least one course of intensive chemotherapy, treated with 5-azacytidine in three different French institutions. The overall response rate was higher (38\%) than in our cohort (21.7\%) and the median OS (9 months) was also slightly higher than in our study (8 months). ${ }^{29}$ However, despite the relatively inferior results compared to the French cohort using 5-azacytidine, our

TABLE 3 Outcomes at 90 days, 1 year, 3 years and 5 years.

\begin{tabular}{|c|c|c|c|c|c|c|}
\hline Outcomes & 90 days & 1 year $(n, \%)$ & 3 years $(n, \%)$ & 5 years $(n, \%)$ & Total (n) & p-value* \\
\hline \multicolumn{7}{|c|}{ Relapse or progression } \\
\hline Relapse & $13 / 23(56.5 \%)$ & $5 / 23(21.7 \%)$ & $3 / 23(13 \%)$ & $2 / 23(8.7 \%)$ & 23 & NR \\
\hline Missing data & - & - & - & - & 38 & \\
\hline \multicolumn{7}{|l|}{ Overall survival } \\
\hline Mortality & $20 / 42(47.6)$ & $18 / 42(42.8 \%)$ & $2 / 42(4.7 \%)$ & $4 / 42(9.5 \%)$ & 42 & $<0.001$ \\
\hline Missing data & & & & & 0 & \\
\hline \multicolumn{7}{|l|}{ TRM } \\
\hline Mortality - TRM & $9 / 15(60 \%)$ & $4 / 15(26.7 \%)$ & $2 / 15(13.3 \%)$ & 0 & 15 & 0.136 \\
\hline Missing data & - & - & - & - & 0 & \\
\hline \multicolumn{7}{|c|}{ Disease mortality } \\
\hline Mortality - AML & $11 / 27(40.7 \%)$ & $14 / 27(51.8 \%)$ & 0 & $4 / 27(14.8 \%)$ & 27 & 0.005 \\
\hline Missing data & - & - & - & - & 0 & \\
\hline
\end{tabular}

n: number of patients; ${ }^{*}$ Chi-square test; NR: not reported; TRM: transplant-related mortality; AML: acute myeloid leukemia. 
cohort provided a high number of patients (61 versus 47) and a similar OS to the 5-azacytidine study. Of note, randomized clinical trials are warranted in order to compare the real effectiveness of both approaches in relapsed/refractory AML patients. In our cohort, conditioning regimen data are reported in Table 2 and Table 3. Myeloablative and non-myeloablative regimen were well balanced and applied at the physician's discretion and according to institutional protocol indications. ${ }^{26}$ In 2012, Bornhäuser et al. ${ }^{30}$ published an interesting phase III trial with 99 patients randomly assigned to receive reduced-intensity regimen and 96 patients to receive standard conditioning regimen. The incidence of non-relapse mortality, relapse incidence at 3 years, PFS at 3 years, and OS at 3 years did not differ significantly between groups. ${ }^{30}$ However, grade III-IV toxicities were less common in the reduced intensity group. This trial was stopped early due to a slow inclusion of patients. The authors concluded that reduced intensity conditioning had similar survival outcomes compared to standard regimens with few side effects and thus should be offered to AML patients aged less than 60 years in first complete remission. ${ }^{30}$ Therefore, we believe that the conditioning regimen used in our study did not affect the outcomes of our set of patients as a confounding factor. However, for those patients who relapse after ASCT, prognosis is particularly poor with limited reported literature addressing this issue. In our study, the majority of patients relapsed in the first 90 days post-ASCT (56.5\%) and a minority relapsed 5 years after ASCT (8.7\%) (Table 3). Likewise, mortality in the first 90 days (47.6\%) and after 1 year $(42.8 \%)$ were higher than the mortality at $3(4.7 \%)$ and 5 years $(9.5 \%)(p<0.001)$. This fact could be due to the extreme agressiveness of the disease, high toxicity grades, and difficult clinical management. In addition, TRM tended to occur in the first 90 days post-ASCT (60\%) compared to the first $(26.7 \%)$ and third years (13.3\%) post-ASCT ( $\mathrm{p}=0.136$ ). In 2013, Lee et al. ${ }^{9}$ published a retrospective study in which they reviewed 49 patients with AML who received ASCT and who had subsequently relapsed. The 5-year OS was $31.6 \%$ and all three recipients of second ASCT died. Thus, Lee et al. concluded that treatment with curative intent was able to save a minor but important subset of patients with AML who relapsed after ASCT. ${ }^{9}$ Notably, even though our patients have been treated with prophylaxis to GVHD with cyclosporine and mycophenolate mofetil, grade II-IV acute GVHD occurred in a considerable number of patients. In 2012, another South Korean study reported a set of 142 consecutive AML patients treated with ASCT who also presented high acute (37.6-53.7\%) and chronic (8.9-19.5\%) GVHD incidence. ${ }^{31}$
In addition, another study ${ }^{32}$ by Baron et al. reported that grade III-IV and extensive GVHD had influence in OS of AML patients treated with ASCT. Thus, improvement in prevention and treatment of severe GVHD could have influence in prognosis of those patients, even though it is a difficult issue to overcome. ${ }^{32}$

\section{Conclusion}

In conclusion, relapsed/refractory AML post-ASCT remains a very aggressive disease. ${ }^{26}$ Many efforts throughout the clinical and scientific communities are underway in order to develop novel strategies for best treatment care. ${ }^{21,25,27}$ Nevertheless, there is still a gray area where the highlights in patient's clinical managements with respect to a best therapeutic choice and side-effects control are the mainstay of this field. In our cohort, TRM remains considerable, but ASCT in this setting seems to be a good choice for AML patients with active disease. However, new approaches are needed in order to reduce TRM, GVHD incidence and relapse in this set of patients.

\section{Resumo}

Resultados do transplante alogênico de células-tronco em doentes com leucemia mieloide aguda com doença ativa: experiência de um único Centro Oncológico Europeu

Introdução: o transplante alogênico de células-tronco hematopoiéticas (TCTH-alo) representa uma abordagem potencialmente curativa para pacientes com leucemia mieloide aguda (LMA) recorrente ou refratária. Nosso trabalho apresenta o resultado de pacientes com recaída ou doença refratária tratados com TCTH-alo.

Método: coorte retrospectiva incluindo 61 pacientes de 1994 a 2013 com diagnóstico de recidiva/LMA refratária. Os desfechos de interesse foram mortalidade relacionada ao transplante (MRT), incidência da doença aguda e crônica do enxerto contra hospedeiro (DECH), incidência de recaídas, sobrevida livre de progressão (PFS - progression-free survival) e sobrevida global (SG). A significância estatística foi considerada para $\mathrm{p}<0,05$.

Resultados: a média de idade foi de 61 anos (variação de 1 a 65). A incidência cumulativa de 90 dias, 1 ano e 3 anos de MRT foram de $60 \%, 26,7 \%$ e $13,3 \%$, respectivamente ( $\mathrm{p}<0,001)$. A incidência de recaída foi de $21,7 \%$ em 1 ano, $13 \%$ em 3 anos e 8,7\% em 5 anos. A SG mediana foi estimada em 8 meses (IC 95\% 3,266-12,734) e a mediana de PFS, em 3 meses (IC 95\% 1,835-4,165).

Conclusão: em nossa coorte, MRT no primeiro ano após o transplante permanece considerável, mas TCTH-alo 
nesse cenário parece ser uma boa opção para pacientes com LMA ativa. No entanto, novas abordagens são necessárias para reduzir MRT e recaída nesse conjunto de pacientes.

Palavras-chave: leucemia mieloide aguda, transplante heterólogo, neoplasias da medula óssea.

\section{REFERENCES}

1. Mohty M. Indications for HSCT in adults: acute myeloid leukaemia. In: Appertley J, Carreras E, Gluckan E, Masszi T, editors. The EBMT handbook - haematopoietic stem cell transplantation. 6. ed. Paris: ESH - European School of Haematology; 2012. p. 317-29.

2. Bishop MR, Tarantolo SR, Geller RB, Lynch JC, Bierman PJ, Pavletic ZS, et al. A randomized, double-blind trial of filgrastim (granulocyte colonystimulating factor) versus placebo following allogeneic blood stem cell transplantation. Blood. 2000; 96(1):80-5.

3. Yanada M, Matsuo K, Emi N, Naoe T. Efficacy of allogeneic hematopoietic stem cell transplantation depends on cytogenetic risk for acute myeloid leukemia in first disease remission. Cancer. 2005; 103(8):1652-8.

4. Grimwade D, Walker H, Oliver F, Wheatley K, Harrison C, Harrison G, et al. The importance of diagnostic cytogenetics on outcome in AML: analysis of 1,612 patients entered into the MRC AML 10 trial. Blood. 1998; 92(7):2322-33.

5. Slovak ML, Kopecky KJ, Cassileth PA, Harrington DH, Theil KS, Mohamed A, et al. Karyotypic analysis predicts outcome of preremission and postremission therapy in adult acute myeloid leukemia: a Southwest Oncology Group/ Eastern Cooperative Oncology Group Study. Blood. 2000; 96(13):4075-83.

6. Jourdan E, Boiron J-M, Dastugue N, Vey N, Marit G, Rigal-Huguet F, et al. Early allogeneic stem-cell transplantation for young adults with acute myeloblastic leukemia in first complete remission: an intent-to-treat longterm analysis of the BGMT experience. J Clin Oncol. 2005; 23(30):7676-84

7. Abrahamsson J, Clausen N, Gustafsson G, Hovi L, Jonmundsson G, Zeller B, et al.; Nordic Society for Paediatric Haematology and Oncology (NOPHO). Improved outcome after relapse in children with acute myeloid leukaemia. Br J Hematol. 2007; 136(2):229-36.

8. Gibson BE, Webb DK, Howman AJ, De Graaf SS, Harrison CJ, Wheatley K; United Kingdom Childhood Leukaemia Working Group and the Dutch Childhood Oncology Group. Results of a randomized trial in children with acute myeloid leukaemia: medical research council AML12 trial. Br J Hematol. 2011; $155(3): 366-76$

9. Lee JW, Jang PS, Chung NG, Cho B, Kim HK. Treatment of children with acute myeloid leukaemia who relapsed after allogeneic haematopoietic stem cell transplantation. Br J Hematol. 2013; 160(1):80-6.

10. Burke M, Gossai N, Cao Q, MacMillan M, Warlick E, Verneris M. Similar outcomes between adolescent/young adults and children with AML following allogeneic hematopoietic cell transplantation. Bone Marrow Transplant. 2014; 49(2):174-8.

11. Robitaille N, Lacroix J, Math LAM, Clayton L, Cortier M, Schultz KR, et al. Excess of veno-occlusive disease in a randomized clinical trial on a higher trigger for red blood cells transfusion after bone marrow transplantation: a Canadian Blood and Marrow Transplant Group Trial. Biol Blood Marrow Transplant. 2012; 19(3):468-73.

12. Przepiorka D, Smith TL, Folloder J, Anderlini P, Chan K-W, Körbling M, et al. Controlled trial of filgrastim for acceleration of neutrophil recovery after allogeneic blood stem cell transplantation from human leukocyte antigenmatched related donors. Blood. 2001; 97(11):3405-10.

13. Shimoni A, Nagler A. Optimizing the conditioning regimen for allogeneic stem-cell transplantation in acute myeloid leukemia; dose intensity is still in need. Best Pract Res Clin Haematol. 2011; 24(3):369-79.

14. Shimoni A, Shem-Tov N, Volchek Y, Danylesko I, Yerushalmi R, Nagler A. Allo-SCT for AML and MDS with treosulfan compared with BU-based regimens: reduced toxicity vs reduced intensity. Bone Marrow Transplant. 2012; 47(10):1274-82

15. Kaspers GJ, Zwaan CM. Pediatric acute myeloid leukemia: towards highquality cure of all patients. Haematologica. 2007; 92(11):1519-32.
16. Martino R, Caballero MaD, Pérez-Simón JA, Canals C, Solano C, UrbanoIspizua A, et al.; AML and alloPBSCT Subcommittees of the Spanish Group for Hematopoietic Transplantation. Evidence for a graft-versus-leukemia effect after allogeneic peripheral blood stem cell transplantation with reduced-intensity conditioning in acute myelogenous leukemia and myelodysplastic syndromes. Blood. 2002; 100(6):2243-5.

17. de Lima M, Anagnostopoulos A, Munsell M, Shahjahan M, Ueno N, Ippoliti $\mathrm{C}$, et al. Nonablative versus reduced-intensity conditioning regimens in the treatment of acute myeloid leukemia and high-risk myelodysplastic syndrome: dose is relevant for long-term disease control after allogeneic hematopoietic stem cell transplantation. Blood. 2004; 104(3):865-72.

18. Russo D, Malagola M, Vivo A, Fiacchini M, Martinelli G, Piccaluga PP, et al. Multicentre phase III trial on fludarabine, cytarabine (Ara-C), and idarubicin versus idarubicin, Ara-C and etoposide for induction treatment of younger, newly diagnosed acute myeloid leukaemia patients. Br J Haematol. 2005; 131(2):172-9.

19. Wiernik PH, Banks P, Case DJ, Arlin ZA, Periman P, Todd M, et al. Cytarabine plus idarubicin or daunorubicin as induction and consolidation therapy for previously untreated adult patients with acute myeloid leukemia. Blood. 1992; 79(2):313-9.

20. Daver N, Cortes J. Molecular targeted therapy in acute myeloid leukemia. Hematology. 2012; 17(Suppl 1):s59-62.

21. Tauro S, Craddock C, Peggs K, Begum G, Mahendra P, Cook G, et al. Allogeneic stem-cell transplantation using a reduced-intensity conditioning regimen has the capacity to produce durable remissions and long-term disease-free survival in patients with high-risk acute myeloid leukemia and myelodysplasia. J Clin Oncol. 2005; 23(36):9387-93.

22. Chauncey TR, Rankin C, Anderson JE, Chen I, Kopecky KJ, Godwin JE, et al. A phase I study of induction chemotherapy for older patients with newly diagnosed acute myeloid leukemia (AML) using mitoxantrone, etoposide, and the MDR modulator PSC 833: a southwest oncology group study 9617. Leukemia Res. 2000; 24(7):567-74.

23. Wolff SN, Herzig RH, Fay JW, Phillips GL, Lazarus HM, Flexner JM, et al. High-dose cytarabine and daunorubicin as consolidation therapy for acute myeloid leukemia in first remission: long-term follow-up and results. J Clin Oncol. 1989; 7(9):1260-7.

24. Mayer RJ, Davis RB, Schiffer CA, Berg DT, Powell BL, Schulman P, et al. Intensive postremission chemotherapy in adults with acute myeloid leukemia. Cancer and Leukemia Group B. N Engl J Med. 1994; 331(14):896-903.

25. Craddock C, Tauro S, Moss P, Grimwade D. Biology and management of relapsed acute myeloid leukaemia. Br J Haematol. 2005; 129(1):18-34.

26. Creutzig U, Reinhardt D. Current controversies: which patients with acute myeloid leukaemia should receive a bone marrow transplantation? - A European view. Br J Haematol. 2002; 118(2):365-77.

27. Chen AR, Alonzo TA, Woods WG, Arceci RJ. Current controversies: which patients with acute myeloid leukaemia should receive a bone marrow transplantation? - An American view. Br J Haematol. 2002; 118(2):378-84.

28. Hospital MA, Thomas X, Castaigne S, Raffoux E, Pautas C, Gardin C, et al. Evaluation of allogeneic hematopoietic SCT in younger adults with adverse karyotype AML. Bone Marrow Transplant. 2012; 47(11):1436-41.

29. Ivanoff S, Gruson B, Chantepie SP, Lemasle E, Merlusca L, Harrivel V, et al. 5-Azacytidine treatment for relapsed or refractory acute myeloid leukemia after intensive chemotherapy. Am J Hematol. 2013; 88(7):601-5.

30. Bornhäuser M, Kienast J, Trenschel R, Burchert A, Hegenbart U, Stadler M, et al. Reduced-intensity conditioning versus standard conditioning before allogeneic haemopoietic cell transplantation in patients with acute myeloid leukaemia in first complete remission: a prospective, open-label randomised phase 3 trial. Lancet Oncol. 2012; 13(10):1035-44.

31. Lee SJ, Kang BW, Moon JH, Chae YS, Kim JG, Jung JS, et al. Comparable analysis of outcomes for allogeneic peripheral blood stem cell transplantation from matched related and matched unrelated donors in acute myeloid leukemia. Acta Haematol. 2011; 127(2):81-9.

32. Baron F, Labopin M, Niederwieser D, Vigouroux S, Cornelissen J, Malm C, et al. Impact of graft-versus-host disease after reduced-intensity conditioning allogeneic stem cell transplantation for acute myeloid leukemia: a report from the Acute Leukemia Working Party of the European group for blood and marrow transplantation. Leukemia. 2012; 26(12):2462-8 